\title{
LAROYÊ EXU: QUIMBANDA EM MADRID
}

\author{
Lorran Lima $\mathbb{Q}$
}

Universidade Federal do Rio Grande do Norte

Grupo de Estudos sobre Culturas Populares I Natal - RN - Brasil 
O convite para visitar o Centro de Estudos Comparatistas da Universidade de Lisboa, feito pela Doutora Clara Saraiva, foi a porta de acesso para o desenvolvimento do trabalho ora apresentando neste ensaio, que me proporcionou conhecer um pouco da dinâmica das religiões afro-brasileiras em Lisboa e em Madrid. As fotos publicadas aqui foram feitas especialmente durante uma cerimônia para Exu Giramundo, no Ilê Ogum Oia Axé Odara, onde são realizados cultos de Umbanda, Quimbanda e Nação Gêge Ijexá, reconhecidos pela Federação Brasileira de Umbanda.

As fotos presentes neste ensaio (Figuras 1 a 8) foram feitas por meio de uma câmera Sony Cyber-shot DSC-W570 e editadas no programa Adobe Photoshop CS6. A cerimônia foi executada apenas com luzes led roxas, instaladas no teto da casa. Optei por não utilizar o flash da câmera, em respeito à ocasião, por isso a captura do evento foi feita em baixa luminosidade. A seleção de imagens buscou permitir que o leitor observe a cronologia da cerimônia.

A Quimbanda é identificada por trabalhar com entidades consideradas de esquerda dentro da Umbanda, ou seja, Exus e Pombas Giras, por vezes, consideradas entidades com alto poder para magias. Essas entidades são tidas como mensageiros entre os homens e as divindades. Exus e Pombas Giras trabalham vencendo demandas e em busca de sua evolução espiritual.

O Ilê presente em Madrid pode ser observado como uma representação da transnacionalização dos cultos afro-religiosos para a Europa. O Babalorixá Walter Egea, hoje com 55 anos, começou sua vida religiosa no Uruguai, onde nasceu. Anos depois, o Babalorixá morou no Brasil, onde deu continuidade aos seus preceitos religiosos e, atualmente, conta com mais de três anos do funcionamento de seu Ilê em Madrid, sendo dirigente de casas afro-religiosas há 14 anos.

A seguir, descrevo as etapas da cerimônia: o início foi constituído com o Babalorixá Walter Egea se posicionando à frente do altar de Exu, fazendo saudações a Ele. Os participantes, que estavam organizados em forma de círculo, também faziam a saudação a Exu: "Laroyê Exu" (Figura 1). Em seguida, Exu Giramundo incorpora em seu "cavalo", conceito dado para os sacerdotes antes da incorporação. A partir desse momento, Exu Giramundo está em terra (Figura 2). Já com Exu Giramundo em terra, todas as pessoas da casa são cumprimentadas e recebem a benção da entidade, que dirige a cerimônia com cânticos, recebendo também as outras entidades na casa (Figura 3).

Então, Exu Giramundo recebe a presença da Pomba Gira Maria Padilha, que figura como sua companhia durante a cerimônia e 
que incorpora em Carmen Valero, cônjuge do Babalorixá Walter Egea (Figura 4). As Pombas Giras são entidades com apresentação feminina pertencentes tanto à Umbanda como à Quimbanda. Já em terra, dona Maria Padilha também saúda todas as pessoas presentes. Após a presença das duas maiores entidades da casa, os membros do Ilê também recebem seus respectivos Exus e Pombas Giras (Figura 5). Ao som de atabaques, todos dançam e cantam os pontos de suas respectivas entidades.

Durante a cerimônia, Exu Giramundo conversou com os convidados falando sobre experiências de vida e dando orientações sobre como se comportar e viver bem, falando em alguns momentos como as pessoas estão se sentindo e o que devem esperar para um futuro próximo (Figura 6).

As entidades ficam no salão, cantando seus pontos. A seguir, eles se despedem dos patronos da cerimônia para deixarem seus "cavalos" (Figura 7).

Ao final, há o momento para o banquete (Figura 8). Tudo o que está na mesa é ligado ao ritual, representando elementos da natureza e os Exus: a carne moída dentro do pimentão vermelho, por exemplo, é servida para dar axé de amor e superação de obstáculos; o molho representa a festa; a farofa de carne moída simboliza as comidas do Exu e da Pomba Gira da casa; os frutos representam todo povo de Exu da casa e, principalmente, o povo do Oriente; os ovos fazem analogia à vida. 

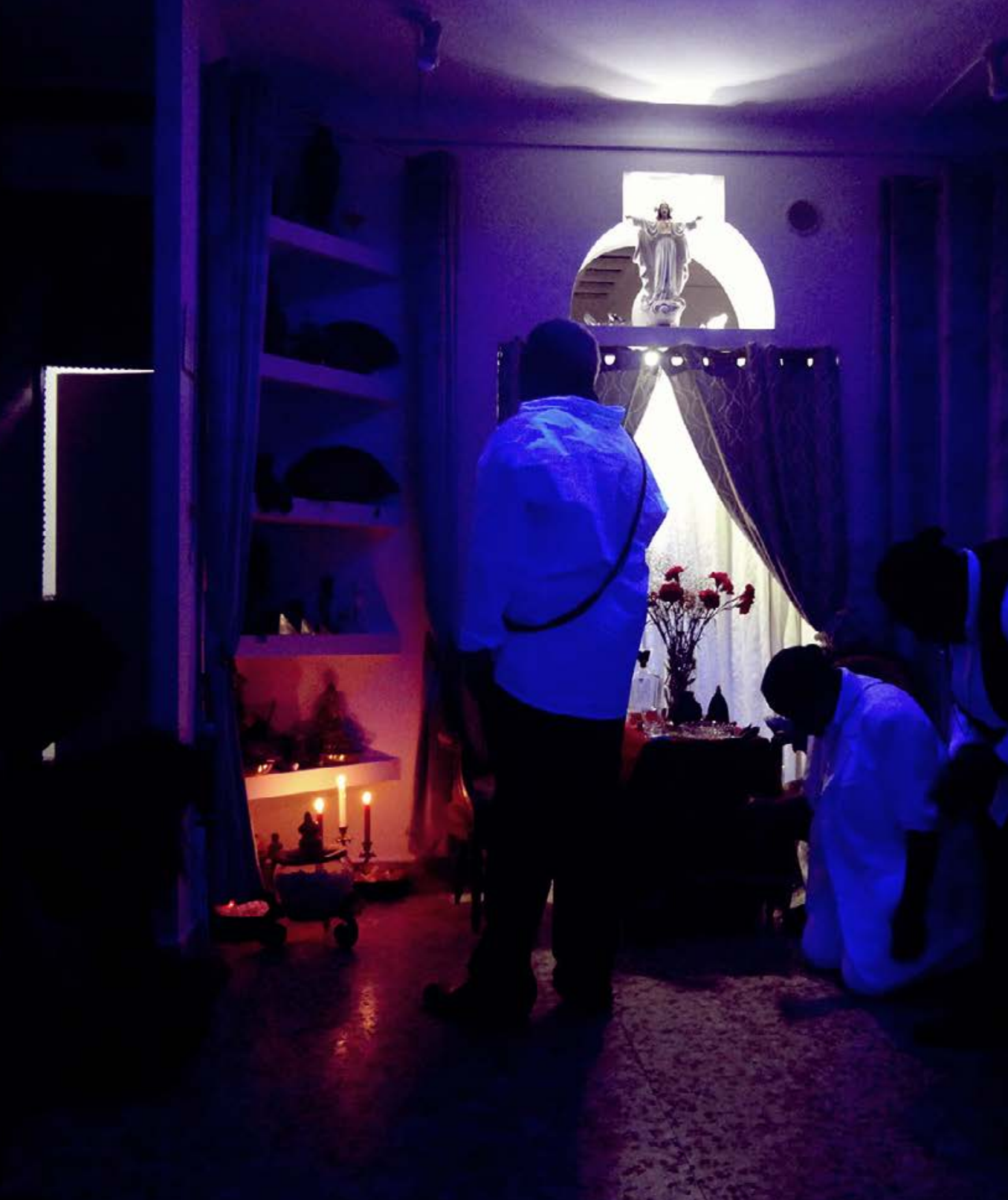

tinas

Figura 1 - Salve o mensageiro curador. Foto: Lorran Lima (2019). 

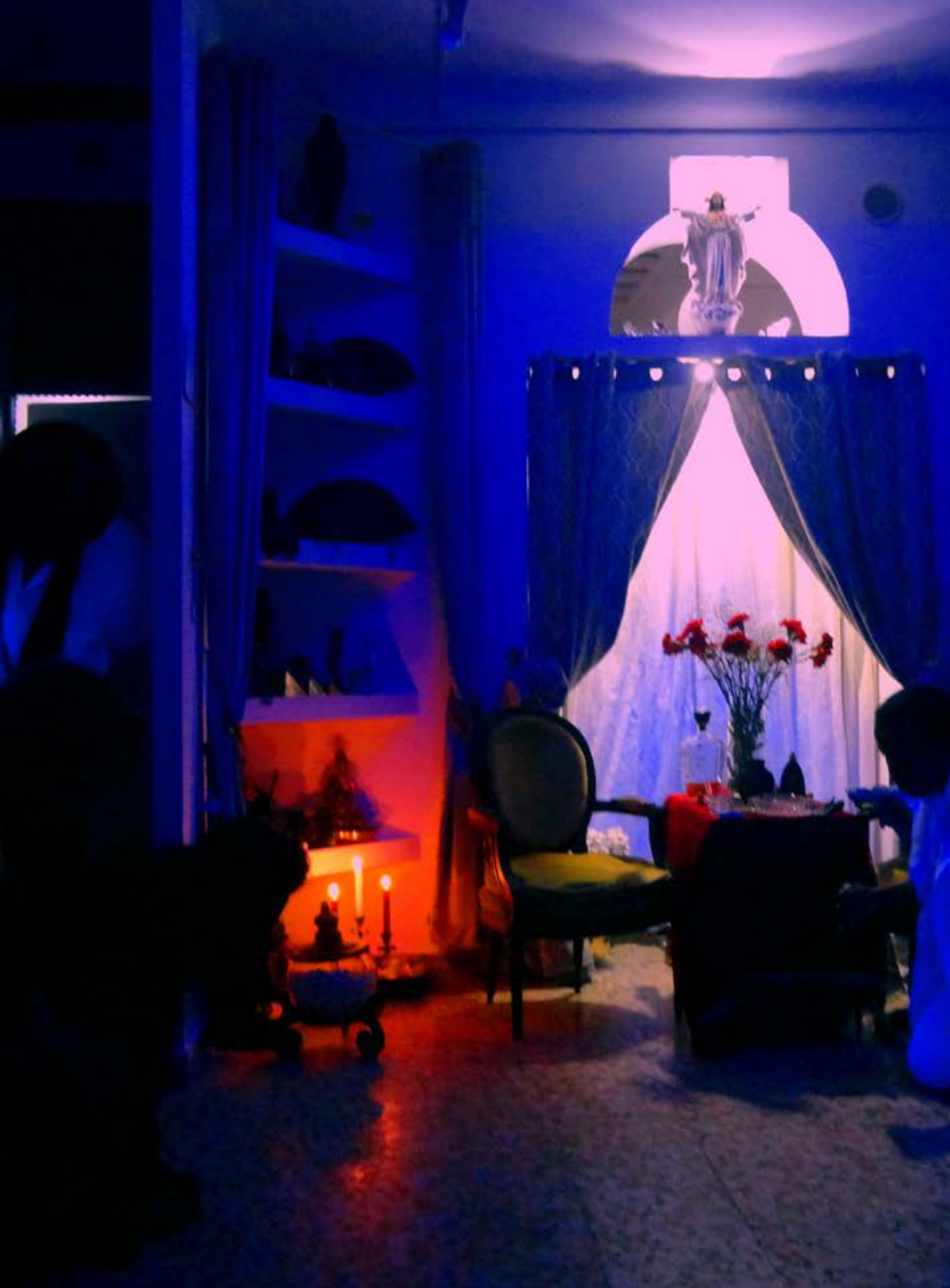

Figura 2 - Exu Giramundo. Foto: Lorran Lima (2019). 


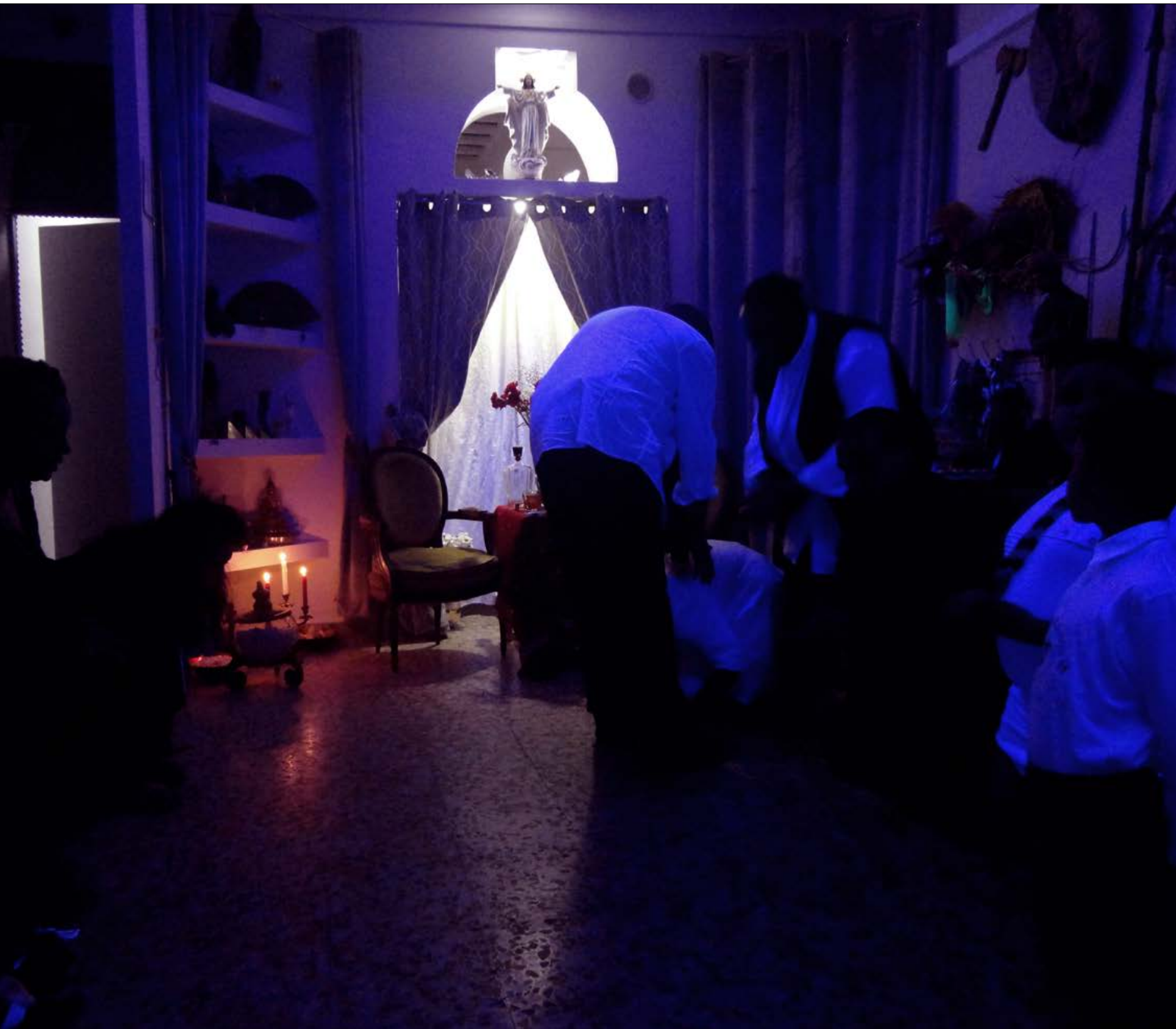

Figura 3 - A benção de Exu. Foto: Lorran Lima (2019). 

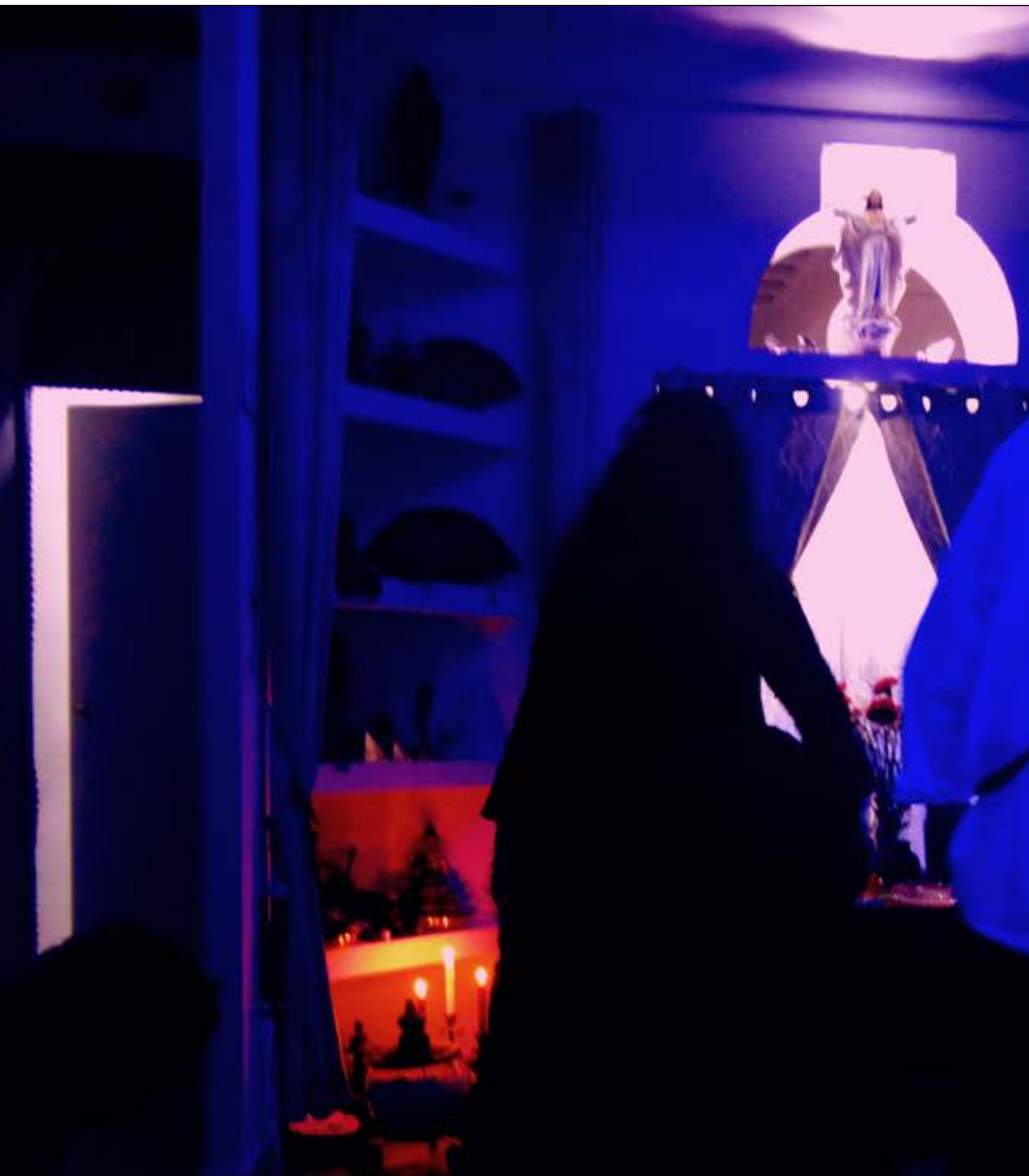

Figura 4 - Pomba Gira Maria Padilha. Foto: Lorran Lima (2019). 


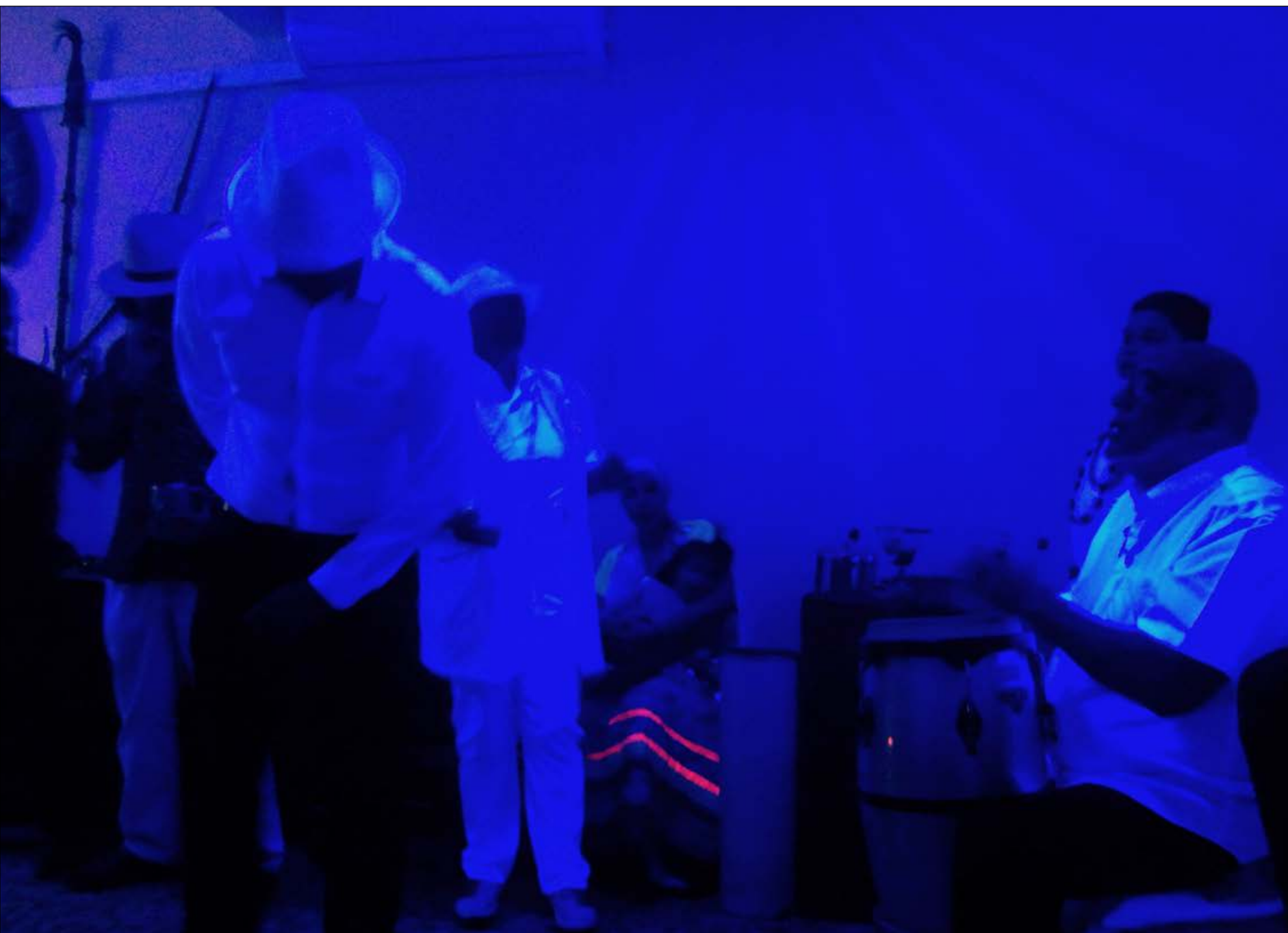

Figura 5 - Entre Exus e Pombas Giras. Foto: Lorran Lima (2019). 


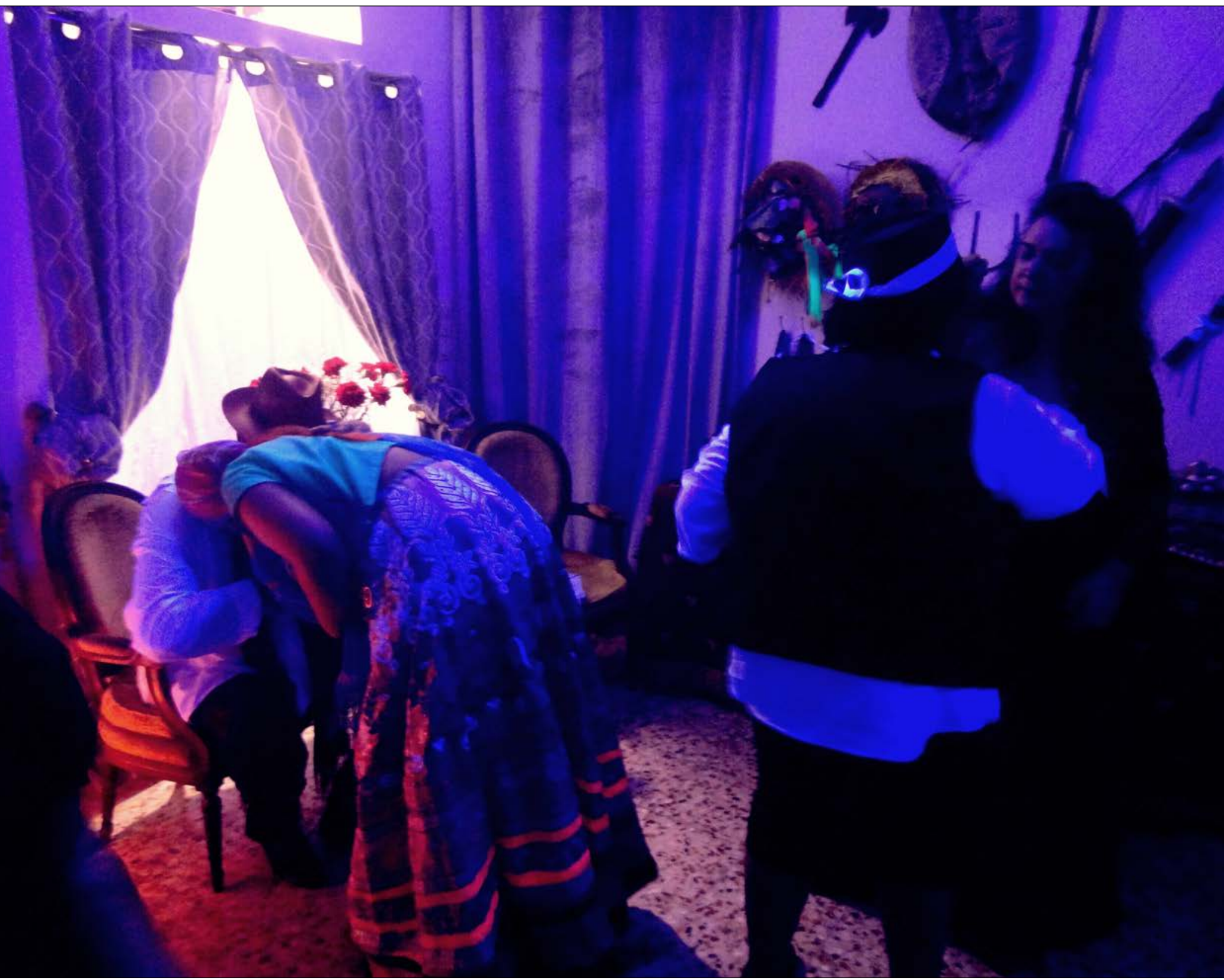

Figura 7 - Despedida das entidades. Foto: Lorran Lima (2019) 
